\title{
Bainite formation influenced by large stress
}

\author{
K. Hase, C. Garcia-Mateo and H. K. D. H. Bhadeshia
}

By using an iron alloy that transforms slowly to bainite at a low temperature, it has been possible to study the development of the upper bainite under the influence of exceptionally large stresses, which are nevertheless below the yield strength of the parent austenite. It is found that a uniaxial stress whose magnitude is below the elastic limit, strongly favours the growth of compliant variants, leading to an organised microstructure. It also accelerates the overall rate of reaction. A comparison between samples transformed with and without an applied stress revealed significant changes in the crystallographic texture, consistent with the observed microstructures. Stress assisted transformation resulted in large blocks of bainite in identical orientation.

MST/6165

Keywords: Bainite, Stress, Phase transformation, Orientation imaging

The authors are in the Department of Materials Science and Metallurgy, University of Cambridge, Pembroke Street, Cambridge CB2 3QZ, UK (hkdb@cus.cam.ac.uk). Manuscript received 11 March 2004; accepted 15 July 2004.

(C) 2004 Institute of Materials, Minerals and Mining. Published by Maney on behalf of the Institute.

\section{Introduction}

The growth of bainite causes a change in the shape of the transformed region. This invariant plane strain (IPS) consists of a large shear component $(s \simeq 0 \cdot 26)$ and a dilatational strain $(\delta \simeq 0.03)$ directed normal to the habit plane. ${ }^{1-6}$ In plain language, this means that the transformation involves not only a change in the crystal structure, but also a deformation. Like normal plastic deformation, bainite should therefore react to an applied stress, essentially in the manner described originally by Patel and Cohen. ${ }^{7}$

Internal stresses caused by martensitic transformation are known to accelerate bainite formation. ${ }^{8,9}$ A similar effect is observed when lower bainite precedes upper bainite. $^{10}$

Applied stresses fall into two categories; those in the elastic range and others which exceed the yield strength of austenite $\sigma_{\gamma}$; in the latter case plastic deformation of austenite precedes phase transformation. Compressive or tensile stresses in the elastic range add to the driving force for transformation and hence tend to accelerate the rate of reaction. ${ }^{11-13}$ When the stress exceeds $\sigma_{\gamma}$, the defects introduced by deformation enhance the nucleation rate and hence the overall rate of reaction increases. However, large plastic strains retard the progress of transformation by interfering with the motion of the glissile bainite/ austenite interfaces, a process known as mechanical stabilisation [reviewed in Refs 3 and 14].

Another consequence of applied stresses is to favour the growth of certain crystallographic variants of bainite which best comply with the stress. This is analogous to the operation, during plastic deformation, of those slip systems on which the critical resolved shear stress is highest. There are 24 crystallographic variants possible in each austenite grain, of which only a few are able to accommodate the stress, thereby making the microstructure more organised. ${ }^{15-17}$

There are, however, slightly contradictory reports in the literature regarding the response of the microstructure to stress. Umemoto et al. ${ }^{12}$ suggested that the alignment of plates occurs when the applied stress exceeds the yield strength of the austenite, and that there is no significant change in microstructure when the stress is below the elastic limit. This contrasts with what is expected from theory ${ }^{7}$ and revealed by some experiments conducted at low stresses. ${ }^{15,16}$
One problem in experiments designed to study stress affected bainite is that the magnitude of the stress that can be applied without causing plastic deformation prior to transformation is rather small. This is because the yield strength of the austenite decreases rapidly as the temperature is increased into the bainite transformation range. In all cases where $\sigma_{\gamma}$ has been measured, the stress applied during the bainite reaction has been limited to $\leqslant 80 \mathrm{MPa}$. Since the mechanical driving force is related directly to the applied stress, ${ }^{7}$ its magnitude has in previous experiments been a small fraction of the chemical driving force, so that the observed stress effects are correspondingly small.

Steels have emerged in which carbide free bainite can be formed at relatively low temperatures where $\sigma_{\gamma}$ is large, and where the transformation rate is slow, allowing plenty of time for untransformed austenite to reach the desired isothermal transformation temperature. ${ }^{18,19}$ This makes it possible to study stress effects with greater clarity. This was the purpose of the present work.

\section{Experimental procedure}

The composition of the steel used was $\mathrm{Fe}-0 \cdot 79 \mathrm{C}-1 \cdot 56 \mathrm{Si}-$ $1.98 \mathrm{Mn}-0.002 \mathrm{P}-1 \cdot 01 \mathrm{Al}-0 \cdot 24 \mathrm{Mo}-1 \cdot 01 \mathrm{Cr}-1 \cdot 51 \mathrm{Co}$ (wt- $\%$ ). The high carbon steel used has a very simple microstructure, consisting only of bainitic ferrite and retained austenite. ${ }^{19}$ The ultimate phase fractions can be determined using X-ray analysis; these values can then be used to calibrate the dilatometric data. This is important because the transformation strains are not isotropic during stress affected transformation, ${ }^{15}$ making it difficult to deduce the phase fractions from dilatometric data alone. The silicon concentration also ensures the absence of carbide precipitation from austenite during the formation of upper bainitic ferrite. The details of the microstructure and properties have been published elsewhere. ${ }^{18,19}$ The cast ingot $(50 \mathrm{~kg})$ made using electric arc melting, was hot rolled to $40 \mathrm{~mm}$ thick plate, which was then homogenised at $1200^{\circ} \mathrm{C}$ for $48 \mathrm{~h}$ in a vacuum furnace.

Cylindrical specimens of $8 \mathrm{~mm}$ diameter and $12 \mathrm{~mm}$ length were machined for the experiments, which were carried out in an adapted thermomechanical simulator, Thermecmaster Z. This instrument is capable of simultaneously recording the time, temperature, load, and radial strains. A Pt/PtRh (Type R) thermocouple was attached 


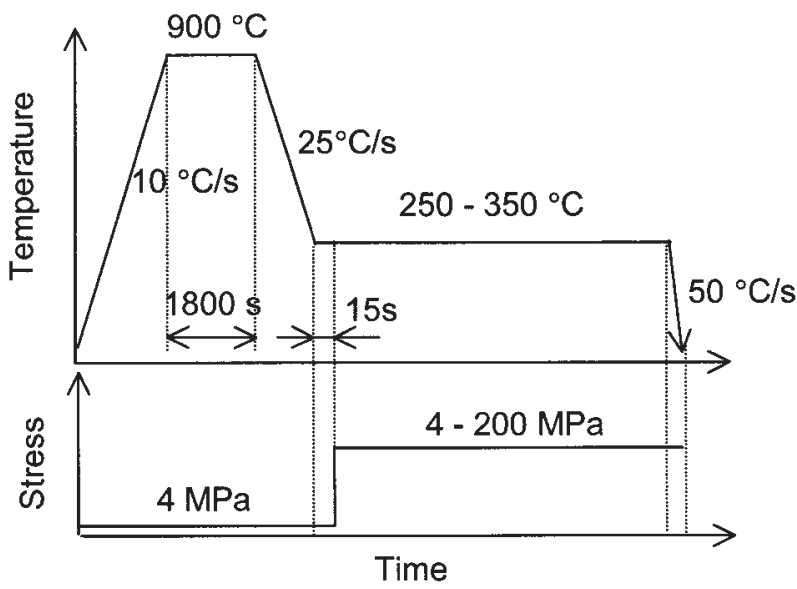

1 Form of mechanical treatment used to study stress affected bainite

centrally by spot welding to the sample surface, to monitor and control specimen temperature. The sample was induction heated in a high vacuum $\left(\sim 4.0 \times 10^{-2} \mathrm{~Pa}\right)$ and cooled to the isothermal transformation temperature range using helium gas quenching. Uniaxial compressive stresses in the range 4-200 $\mathrm{MPa}$ were applied via the servohydraulic system. Note that in the stress free experiments, a small stress of $4 \mathrm{MPa}$ was used to retain the specimen in position. The heat and load schedules utilised are illustrated in Fig. 1.

Optical microscopy and scanning electron microscopy (SEM) were used to characterise the etched microstructures. Specimens were ground and polished using standard techniques and etched in 2 vol. $-\%$ nital solution. The orientations of the traces of bainite sheaf habit planes relative to the stress axis were measured manually using optical microscopy. A $5 \mu \mathrm{m}$ square grid was superimposed on the microstructure and a total of 500 orientations were measured. Vickers hardness was measured with a $30 \mathrm{~kg}$ load.

Quantitative X-ray analysis was used to determine the volume fractions of bainitic ferrite and retained austenite. After grinding and final polishing using $0.1 \mu \mathrm{m}$ diamond paste, the specimens were etched to remove any deformed surface. They were then step scanned in a Philips PW 1730 $\mathrm{X}$-ray diffractometer at $2 \theta$ of $0 \cdot 1^{\circ} \mathrm{min}^{-1}$ over the range $2 \theta=30-110^{\circ}$, with unfiltered $\mathrm{CuK}_{\alpha}$ radiation. The system was operated at $40 \mathrm{kV}$ and $40 \mathrm{~mA}$. The phase fractions were calculated using the integrated intensities of the 111 , 200, 220 and 311 austenite peaks and the 110,002,112 and 022 peaks of ferrite. The use of all these peaks in the analysis reduces bias due to crystallographic texture. ${ }^{20}$ The $\{111\}_{\gamma}$ and $\{110\}_{\alpha}$ peaks show some overlap but they were separated using Reitveld analysis; ${ }^{21}$ the separation process is in this analysis constrained by the information from the other peaks which are isolated.

Electron backscatter diffraction (EBSP) on a scanning electron microscope was used to characterise the distribution of crystallographic orientations in the samples. The system was used in scanning mode to produce orientation maps. The actual instrument used was a TSL OIM on a Hitachi S-4300 scanning electron microscope with a resolution of $0.05 \mu \mathrm{m}$, with measurements done in steps of $0.25 \mu \mathrm{m}$.

\section{Transformation start temperature}

Figure 2 shows the $0 \cdot 2 \%$ proof strength of the austenite, measured using the Thermecmaster, as a function of temperature.

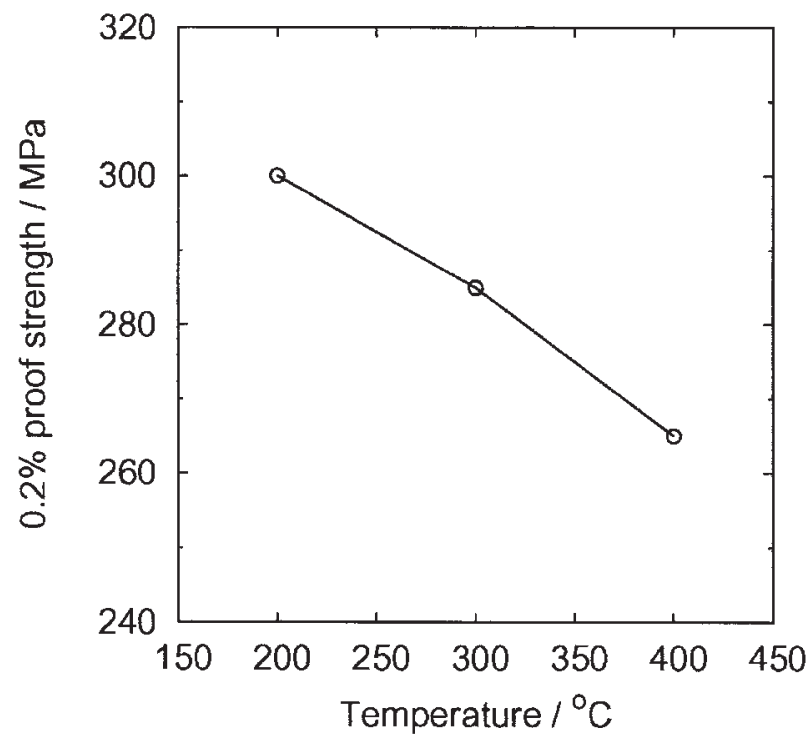

2 Experimentally determined $\mathbf{0 . 2} \%$ proof strength of austenite as function of test temperature

To avoid barreling, $250 \mu \mathrm{m}$ thick sheets of mica were placed between the sample and the Thermecmaster platens. The values illustrated are all greater than the $200 \mathrm{MPa}$ used in subsequent experiments, chosen in order to ensure that it is the effect of stress on the bainite transformation that is characterised; this is in contrast to strain induced transformation. The bainite start temperature was measured to an accuracy of $\pm 5^{\circ} \mathrm{C}$ by conducting a series of isothermal transformation experiments at intervals of $10^{\circ} \mathrm{C}$ for $5 \mathrm{~h}$. The bainite start temperature is determined by the simultaneous conditions ${ }^{22}$

$$
\Delta G^{\gamma \rightarrow \alpha}<-G_{\mathrm{SB}} \text { and } \Delta G_{\mathrm{m}}<G_{\mathrm{N}}
$$

where $\Delta G^{\gamma \rightarrow \alpha}$ is the free energy change associated with the transformation of austenite to ferrite without any composition change, $G_{\mathrm{SB}}=400 \mathrm{~J} \mathrm{~mol}^{-1}$ is the stored energy of bainite, $\Delta G_{\mathrm{m}}$ is the maximum free energy change accompanying the nucleation of bainite and $G_{\mathrm{N}}$ is a universal nucleation function. The details are published elsewhere. ${ }^{22}$

The $\Delta G^{\gamma \rightarrow \alpha}$ can, in the present context, be decomposed into two terms, the chemical driving force $\Delta G_{\mathrm{CHEM}}$ and the mechanical driving force $\Delta G_{\mathrm{MECH}}$, with the latter given by $^{7}$

$$
\begin{aligned}
\Delta G_{\mathrm{MECH}} & =\tau s+\sigma_{N} \delta \\
& \equiv \frac{\sigma}{2}[s \sin 2 \phi-\delta(1+\cos 2 \phi)]
\end{aligned}
$$

where $\sigma$ is the magnitude of the applied uniaxial compressive stress, $\phi$ is the angle between the stress axis and the normal to the habit plane, $\tau$ is the shear stress resolved on the habit plane in the direction of the shear and $\sigma_{\mathrm{N}}$ is the resolved normal stress on the habit plane. As in Ref. 7 it is assumed here that the tensile axis, habit plane normal and shear direction are coplanar, because the purpose here is to calculate the optimum orientation in a polycrystalline sample. The optimum value of $\phi$ can then be obtained from $\tan 2 \phi=-s / \delta .^{7}$ For the values of shear strain and dilatational strain quoted earlier $(0.26$ and 0.03 respectively), this gives $\phi_{\text {optimum }} \simeq 42^{\circ}$.

The chemical driving force was calculated using MTDATA $^{23}$ and the SGTE database. The relative values of the chemical and mechanical components of free energy are illustrated in Fig. 3; $\Delta G_{\mathrm{MECH}}$ is more significant at higher temperatures as $\Delta G_{\mathrm{CHEM}}$ decreases. Figure 3 also shows the partitioning of free energy for experiments done 


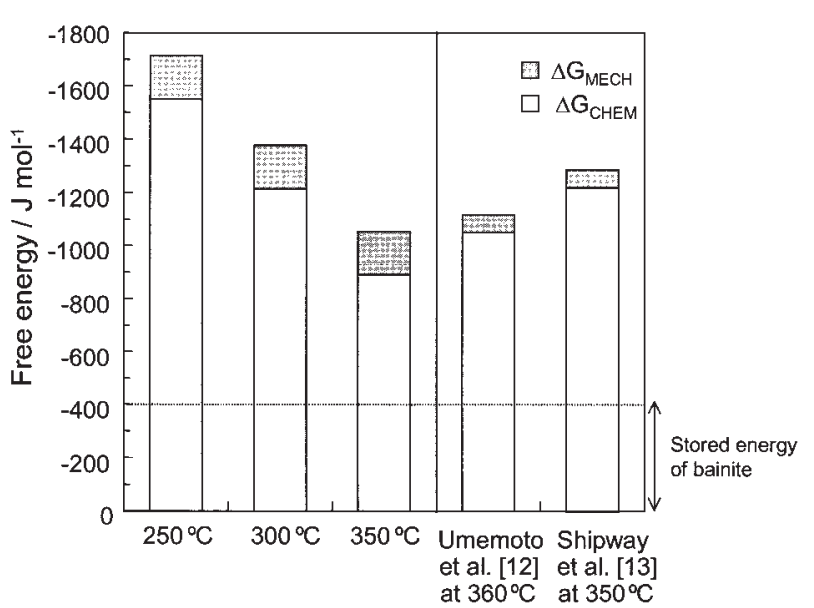

3 Chemical and mechanical components of driving force for bainite growth

in previous work where the stress that could be applied without yielding was smaller.

In fact, the influence of the stress should be greatest at the bainite start temperature $B_{\mathrm{S}}$. Calculations using equations (1) and (2) indicate that a $200 \mathrm{MPa}$ uniaxial, compressive stress should raise $B_{\mathrm{S}}$ by $59^{\circ} \mathrm{C}$; this increase is larger than that observed by $30^{\circ} \mathrm{C}$ from $370^{\circ} \mathrm{C}$ to $400^{\circ} \mathrm{C}$ as the stress was increased from 4 to $200 \mathrm{MPa}$. The reason for this is that the calculations are based on the formation of a crystallographic variant at the optimum orientation. The experiments, on the other hand, are based on
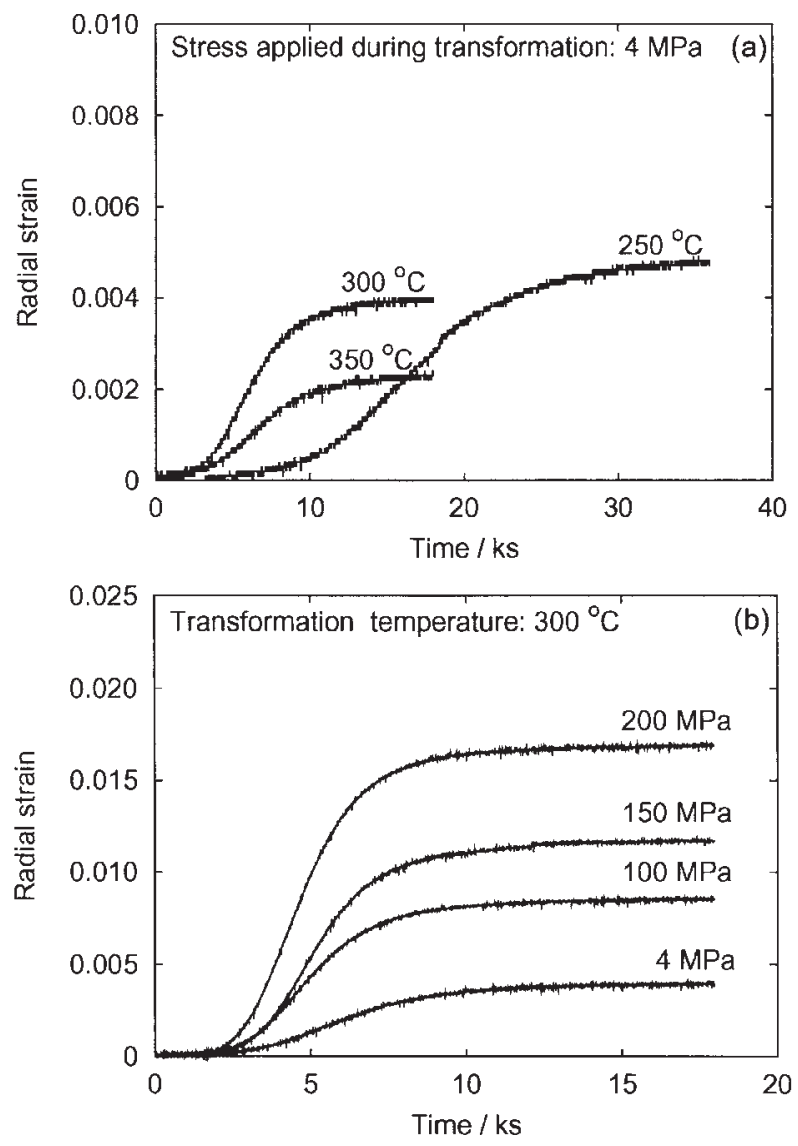

a at various transformation temperatures; $b$ as function of elastic stresses during transformation at $300^{\circ} \mathrm{C}$

4 Change in radial strain associated with bainite transformation

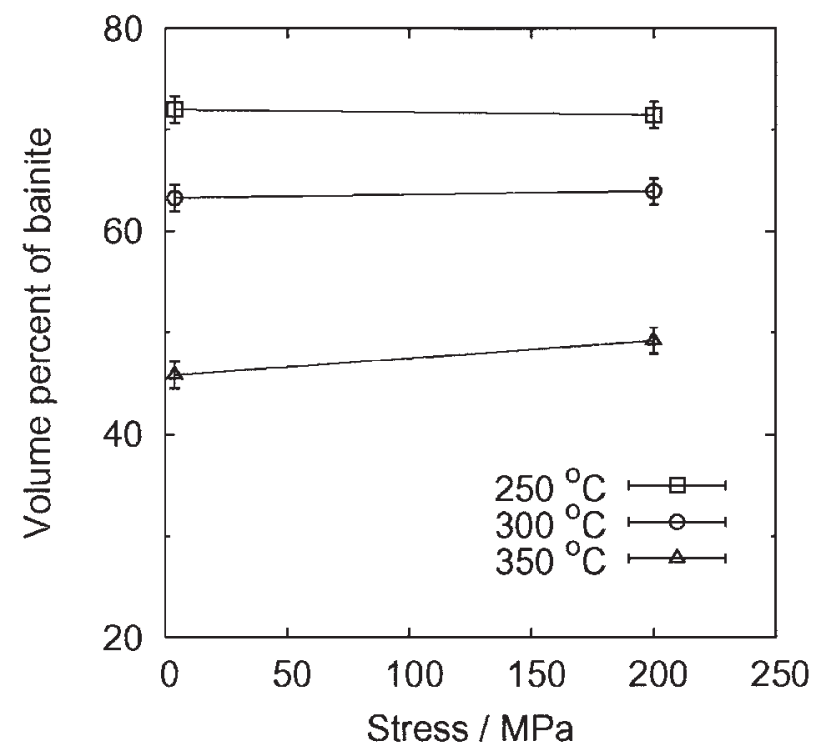

5 Percentage volume of bainite as function of applied stress during transformation and transformation temperature

polycrystalline austenite so the chances of bainite forming at the exact orientation are small.

\section{Kinetics}

Figure $4 a$ shows the radial strain recorded during the course of isothermal transformation to bainite under the influence of negligible stress. Since there will be no favoured variants, the transformation strain averaged over the entire specimen will then be isotropic. ${ }^{15,16}$ The recorded strain is therefore directly related to the volume fraction of bainite.

Figure $4 a$ shows that the maximum extent of transformation increases with the undercooling below $B_{\mathrm{S}}$, as expected from the incomplete reaction phenomenon. ${ }^{3}$ The detailed kinetics follow the classical ' $C$ ' curve behaviour with the maximum rate being at an intermediate temperature.

Figure $4 b$ shows the corresponding data for isothermal transformation at a constant temperature of $300^{\circ} \mathrm{C}$ for a range of compressions.

It is necessary to calibrate the radial strain data against the maximum volume fractions measured using X-ray diffraction; the measurements are illustrated in Fig. 5 for $\sigma=4$ and $200 \mathrm{MPa}$. The error bars plotted indicate the scatter in results when the measurement was repeated three times on the same sample; the errors estimated using the signal to noise ratio from X-ray diffraction data are much smaller. As expected, there is a slight increase in the maximum fraction of bainite as the stress is increased, a consequence of $\Delta G_{\mathrm{MECH}}$. The largest difference is for $350^{\circ} \mathrm{C}$, where the contribution of the mechanical component to the total driving force is largest (Fig. 3). More importantly, the data show vividly that the radial strain cannot be used on its own to determine the fraction of bainite, since the maximum strain observed for $\sigma=200 \mathrm{MPa}$ is about four times that for $4 \mathrm{MPa}$ (Fig. $4 b$ ), but the maximum fractions are comparable (Fig. 5).

The strain data can be normalised using the X-ray measured maximum volume fractions, as illustrated in Fig. 6. The transformation is definitely accelerated by the application of stress for $300^{\circ} \mathrm{C}$ and $350^{\circ} \mathrm{C}$, but the effect is insignificant during transformation at $250^{\circ} \mathrm{C}$, presumably 


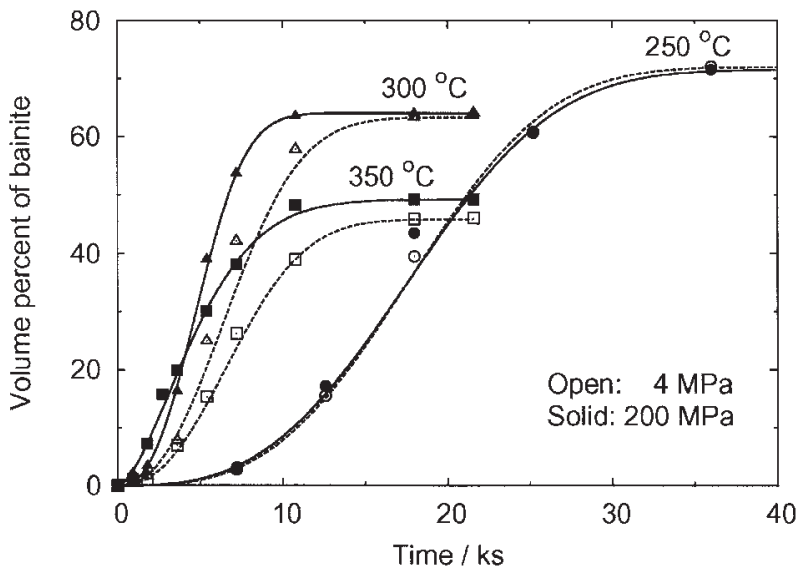

6 Transformation kinetics at different transformation temperatures and stresses because the contribution of $\Delta G_{\mathrm{MECH}}$ is a smaller proportion of the overall driving force (Fig. 3).

\section{Microstructural effects}

Figure 7 shows the remarkable effect that stress has in influencing the development of microstructure during isothermal transformation at $300^{\circ} \mathrm{C}$. There is a clear tendency for the sheaves of bainite to align roughly parallel to the planes of maximum shear stress (the optimum angle would be $42^{\circ}$ ). In the stressed samples, the sheaves tend to be fatter, presumably because they encounter less interference from sheave growing in up to 24 crystallographic variants. The hardness data confirm the dilatometric results that the stress results in an acceleration of the transformation. A substantial reason for the acceleration must be the reduced steric hindrance resulting in fatter sheaves, alongside the contribution from $\Delta G_{\mathrm{MECH}}$.

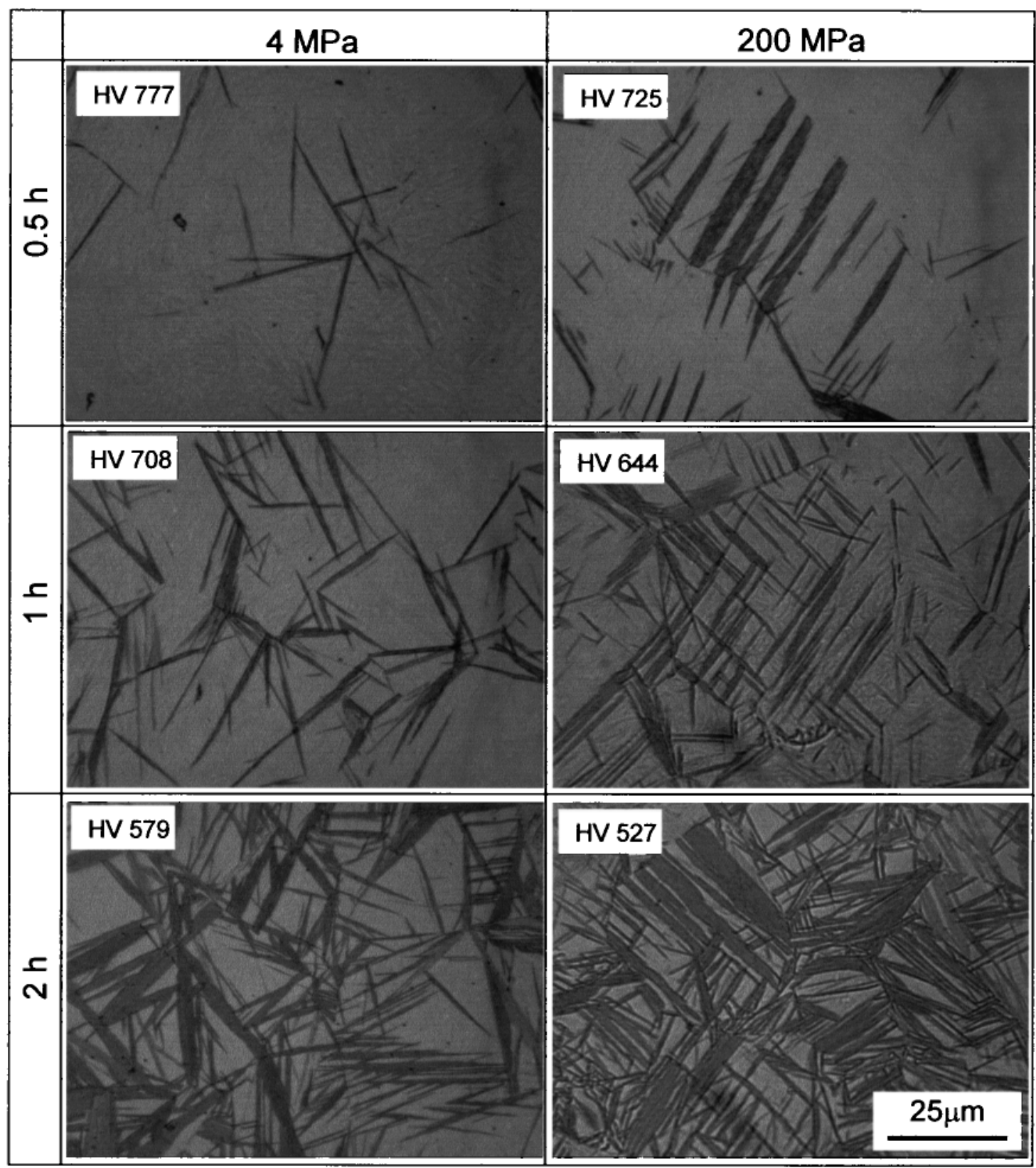

7 Optical micrographs of bainitic microstructure transformed under the influence of applied compressive stress. Stress axis vertical in each case, and transformation temperature $300^{\circ} \mathrm{C}$ 


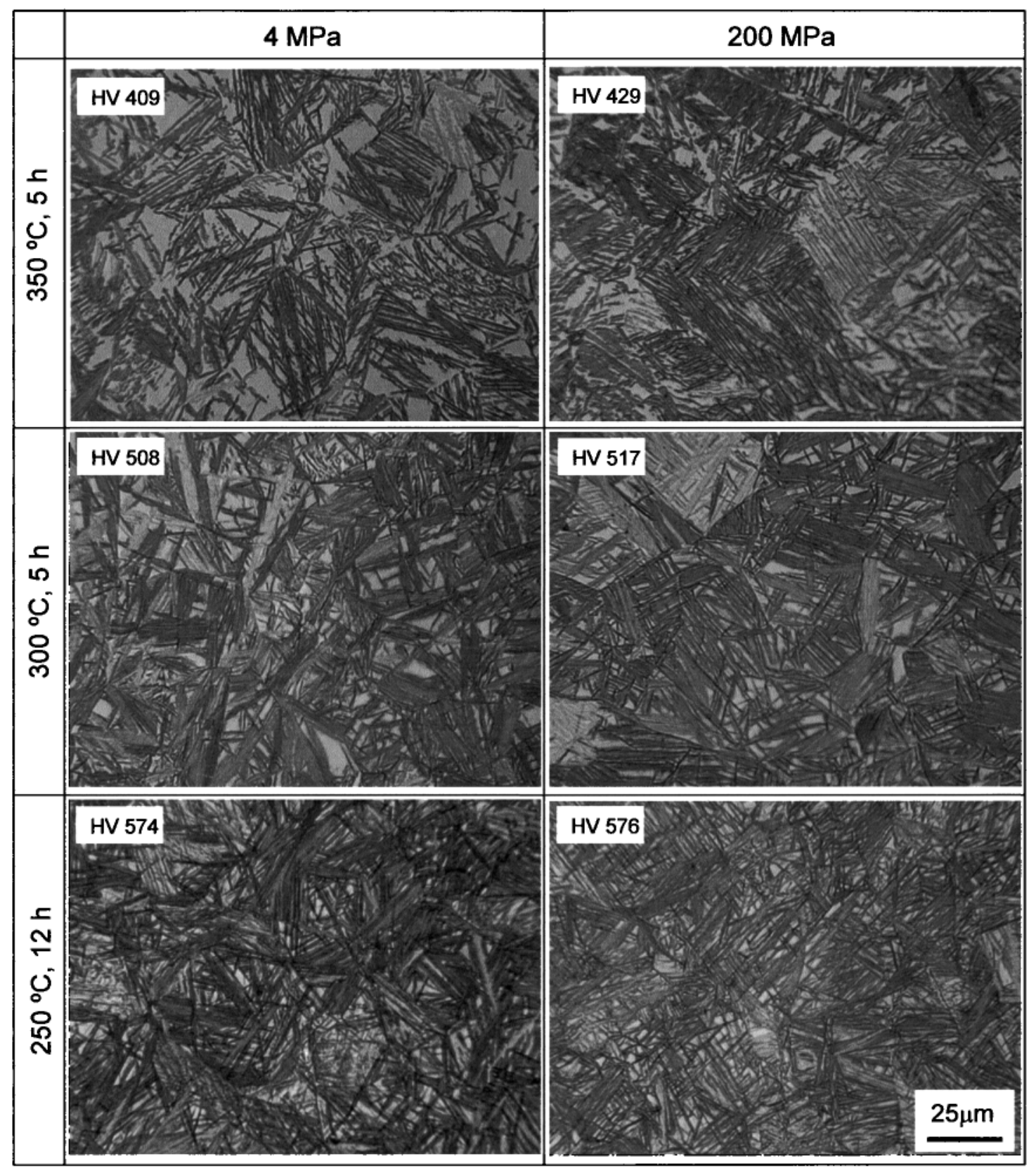

8 Optical micrographs of bainitic microstructure transformed under the influence of applied compressive stress (later stages). Stress axis vertical in each case

Dilatometric results indicated that the residual austenite in samples transformed for only 0.5 and $1 \mathrm{~h}$ at $300^{\circ} \mathrm{C}$ (Fig. 7) tended to partially transform into martensite. However, because this is untempered martensite, it etches very lightly.

Figure 8 shows similar optical micrographs for the late stages of transformation.

The scanning electron micrographs in Fig. 9 vividly illustrate the same phenomenon; the blocks of austenite left untransformed seem finer in the stressed samples, again because the sheaf microstructure is more organised. Judging from previous work on the relative merits of film and blocky austenite, ${ }^{24,25}$ it is speculated that the refined blocks in the stressed samples may be beneficial to the toughness of the steel.

To summarise, there are two effects of stress; first, to decrease the number of crystallographic variants per austenite grain. The second effect is hard to prove given experimental uncertainties, but there appears to be an increase in the fraction of bainite at any stage of transformation based on a consistent interpretation of Xray and hardness data. To express the variant selection more quantitatively, the angles that sheaves make relative to the stress axis were measured as described in the section on experimental techniques. The results are shown in Fig. 10, which is another expression of the clear tendency of the stress to favour variants close to the planes of maximum shear stress.

\section{Crystallographic texture}

Selected experiments were conducted to study the changes in crystallography accompanying the aligned microstructures which form under the influence of stress. Microtextural measurements were made using electron backscatter patterns on a scanning electron microscope. 

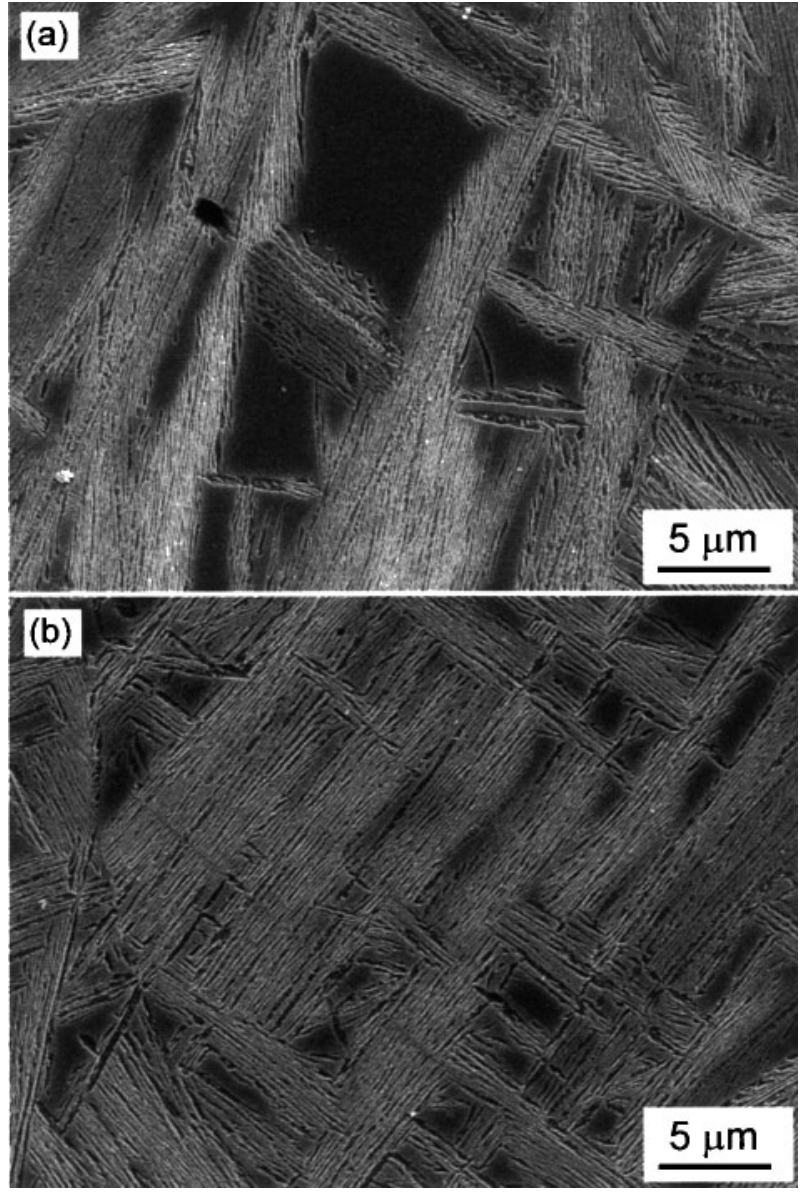

a $4 \mathrm{MPa}$ at $300^{\circ} \mathrm{C}$ for $4 \mathrm{~h}$; b $200 \mathrm{MPa}$ at $300^{\circ} \mathrm{C}$ for $4 \mathrm{~h}$

9 Typical SEM micrograph of bainite transformed under the influence of different applied stresses. Stress axis vertical in each case
Figure 11 shows that there are large regions of parallel sheaves which share a common orientation when the transformation is influenced by stress.

This may be detrimental to toughness since such sheaves may be less effective in hindering the progress of cracks. Using the same technique (EBSP), Gourgues et al. ${ }^{26}$ have, in a different context, shown that propagating cracks are deflected on each encounter with a different orientation.

\section{Conclusions}

It has been possible to study the formation of carbide free bainite under the influence of stresses as large as $200 \mathrm{MPa}$. As a result it has been demonstrated that a compressive, uniaxial stress increases the bainite start temperature and accelerates the transformation. The observed effects are most pronounced at the higher transformation temperatures where the mechanical component of the driving force is relatively large.

The stress also caused microstructural alignment in which selected crystallographic variants of bainite form roughly on the planes of maximum shear stress. The sheaves that grow under the influence of stress are thicker than those transformed ordinarily, due largely to the reduced steric hindrance in the more organised stress affected microstructure. Microtextural measurements indicated that within the limitations of the EBSP technique, the sheaves have uniform orientation.

Further work is required to understand the consequences of the changes in microstructure for the toughness of the steel. Blocks of austenite are refined in the stress affected microstructures, which ought to improved toughness, but the formation of thick sheaves containing platelets in similar crystallographic orientations should have an opposite effect.
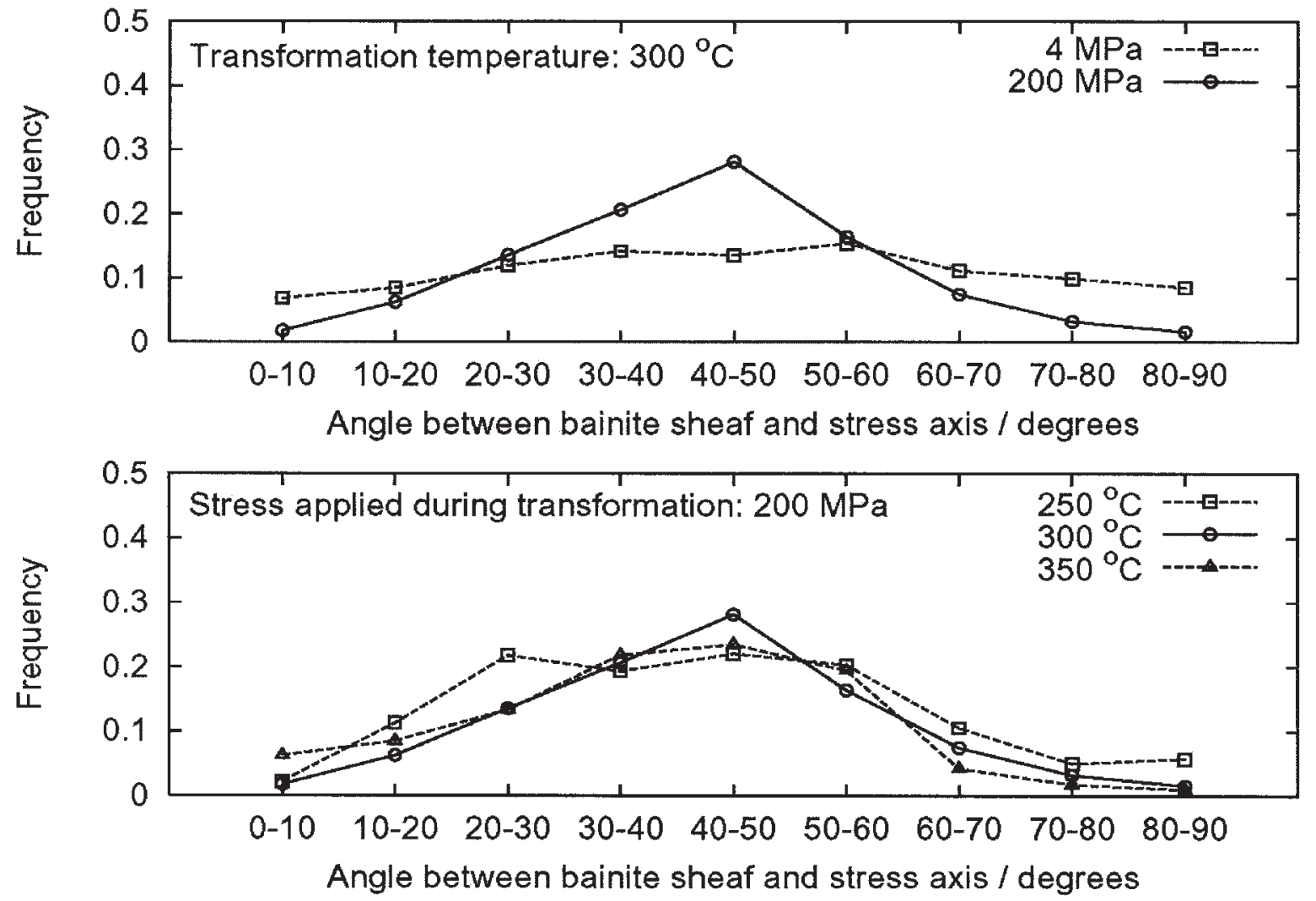

10 Approximate distribution of bainite sheaf traces with respect to longitudinal axis of sample 

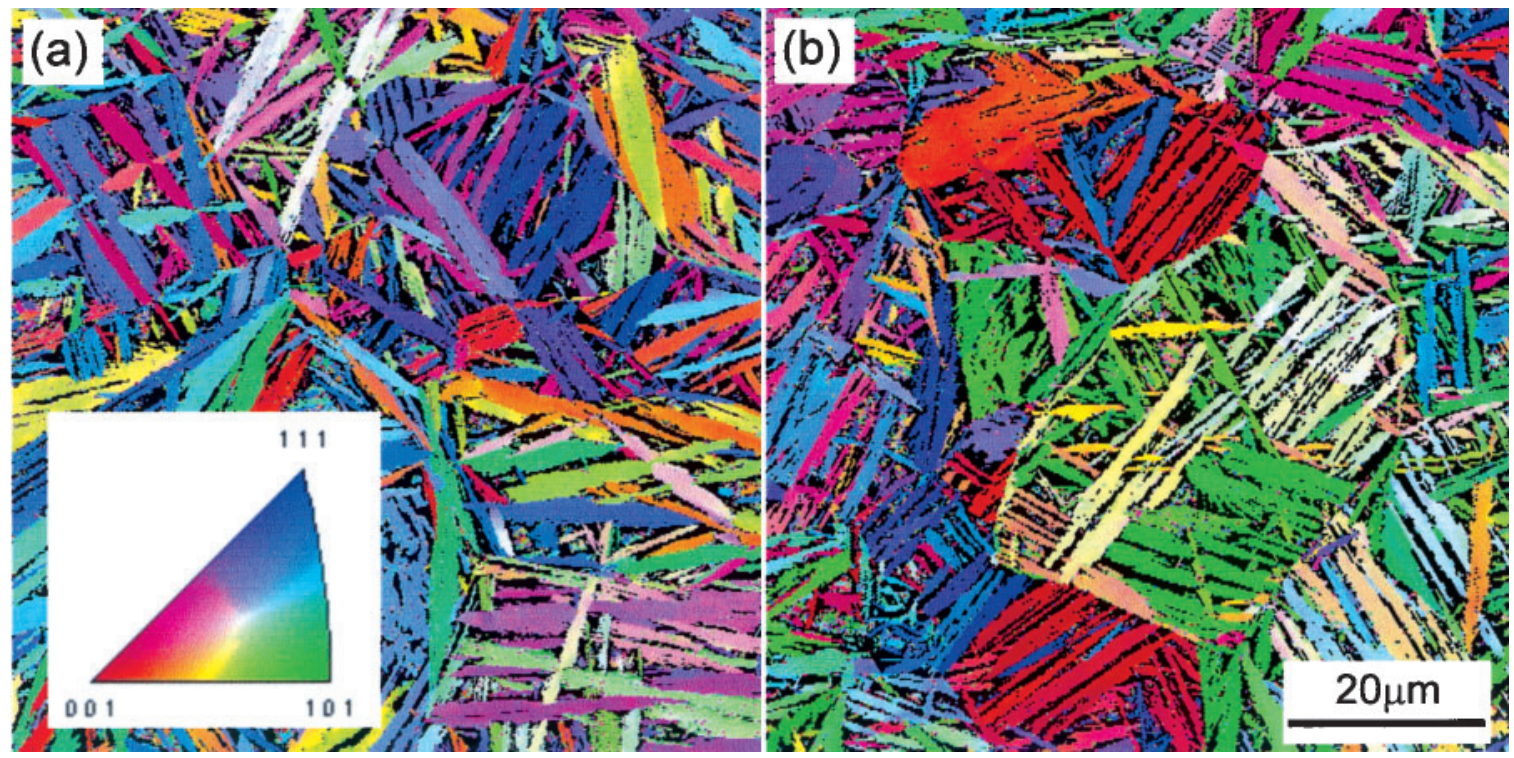

a $4 \mathrm{MPa}$; b $200 \mathrm{MPa}$

11 Orientation imaging maps of bainite formed at $300^{\circ} \mathrm{C}$ for $5 \mathrm{~h}$ under the influence of different applied compressive stresses. Stress axis vertical in each case

\section{Acknowledgements}

The authors are grateful to JFE Steel Corp., Japan and the EPSRC for supporting this work.

\section{References}

1. B. P. J. SANDVIK: Metall. Trans. A, 13A, 777-787.

2. C. M. WAYMAN and H. K. D. H. BHADESHIA: in 'Physical metallurgy', 4th edn (eds R. W. Cahn and P. Hassen), 15071554; 1983, North Holland, Elsevier.

3. H. K. D. H. BHADESHIA: 'Bainite in steels', 2nd edn, 1-458; 2001, London, Institute of Materials.

4. T. KO and S. A. COTTRELL: J. Iron Steel Inst. 1952, 172, 307-313.

5. K. TSUYA: J. Mech. Eng. Lab. Jpn., 1956, 2, 20.

6. E. SWALLOW and H. K. D. H. BHADESHIA: Mater. Sci. Technol., 1995, 11, 109-111.

7. J. R. PATEL and M. COHEN: Acta Metall., 1953, 1, 531-538.

8. R. T. HOWARD and M. COHEN: Trans. AIME, 1948, 176, 384-400.

9. S. V. RADClifFE and E. C. ROLlason: J. Iron Steel Inst., 1959, $191,56-65$.

10. R. H. GOODENOW and R. F. HEHEMANN: Trans. AIME, 1965, 233, 1777 .

11. A. H. COTtRell J. IRON and Steel Inst., 1945, CL1, 93P-104P.
12. M. UMEMOTO, S. BANDO and I. TAMURA: Proc. Int. Conf. on 'Martensitic transformation', 1986, Japan Institute of Metals, 595-600.

13. P. H. ShiPWAY and H. K. D. H. BhADEShia: Mater. Sci. Eng. A, 1995, 201A, 143-149.

14. H. K. D. H. BHADESHIA: Mater. Sci. Eng. A, 1999, A273-275, 5867.

15. H. K. D. H. BHADESHIA, S. A. DAVID, J. M. VITEK and R. W. REED: Mater. Sci. Technol., 1991, 7, 686-698.

16. A. MATSUZAKi, H. K. D. H. BHADEShia and H. HARADA: Acta Metall. Mater., 1994, 42, 1081-1090.

17. L. C. ChANG and H. K. D. H. BHADESHIA: J. Mater. Sci.. 1996, 31. 2145-2148.

18. F. G. CABALLERO, H. K. D. H. BHADEShiA, K. J. A. MAWELLA, D. G. JONES and P. BROWN: Mater. Sci. Technol., 2002, 18, 279-284.

19. C. GARCIA-MATEO, F. G. CABALLERO and H. K. D. H. BHADESHIA: ISIJ Int., 2003, 43, 1238-1243.

20. M. J. J. DICKSON: J. Appl. Crystallogr., 1969, 2, 176-180.

21. D. B. WILES and R. A. YOUNG: J. Appl. Crystallogr., 1981, 14, 149.

22. H. K. D. H. BHADESHIA: Acta Metall., 1981, 29, 1117-1130.

23. MTDATA: 'Phase diagram calculation software', National Physical Laboratory, Teddington, UK 2003.

24. H. K. D. H. BHADESHIA and D. V. EDMONDS: Met. Sci., 1983, 17, 411-419.

25. H. K. D. H. BHADESHIA and D. V. EDMONDS: Met. Sci., 1983, 17. 420-425.

26. A. F. GOURGUeS, H. M. Flower and T. C. LINDLeY: Mater. Sci. Technol., 2000, 16, 26-40. 